\title{
A COVID-19 e a determinação social da saúde: um projeto construído coletivamente
}

\author{
Luciana Santos Collier ${ }^{1}$ \\ Orcid: https://orcid.org/0000-0002-7730-5529
}

Carolina Dantas Magalhães Lopes ${ }^{3}$

Orcid: https://orcid.org/0000-0003-4930-7006

\author{
Victória do Livramento ${ }^{2}$ \\ Orcid: https://orcid.org/0000-0003-4851-7589
}

Juliane Menezes da Silva ${ }^{4}$

Orcid: https://orcid.org/0000-0002-7801-5216

\begin{abstract}
Resumo
O ano de 2020 foi interrompido pela pandemia do coronavírus, quando abruptamente universidades, escolas, comércio e serviços não essenciais foram paralisados. Neste contexto adverso foi criado o projeto "A COVID 19 e a determinação social da saúde". Uma pesquisa qualitativa, com enfoque na estratégia do diagnóstico participativo, que buscou debater com a comunidade de uma escola pública federal, localizada em Niterói/RJ, as condições de saúde e vulnerabilidade social impactadas pela pandemia, provocando reflexões e ações sobre as iniquidades em saúde. Neste artigo descrevemos as ações desenvolvidas pelos bolsistas deste projeto, analisando seus desdobramentos sob a luz da teoria da determinação social da saúde e da educação popular em saúde. Apesar das limitações impostas pelo distanciamento social, conseguimos dialogar virtualmente com a comunidade através das ações do projeto, promovendo discussões e reflexões importantes para o fortalecimento mútuo, contra todo tipo de ataque que insiste em aprofundar as desigualdades sociais.
\end{abstract}

Palavras-chave: Coronavírus. Desigualdades sociais. Educação popular. Saúde.

\begin{abstract}
The year 2020 was interrupted by the coronavirus pandemic, when abruptly universities, schools, commerce and non-essential services were paralyzed. In this adverse context, the project "COVID 19 and the social determination of health" was created. A qualitative research, focusing on the strategy of participatory diagnosis, which sought to discuss with the community of a federal public school, located in Niterói / RJ, about the health conditions and social vulnerability impacted by the pandemic, causing reflections and actions on health inequities. In this article, we describe the actions developed by the fellows of this project, analyzing the development of the actions in the light of the theory of social determination of health and popular education in health. Despite the limitations imposed by social distance, we managed to dialogue with the community virtually through the actions of the project, promoting important discussions and reflections for mutual strengthening, against any type of attack that insists on deepening social inequalities.
\end{abstract}

Keywords: Coronavirus. Social inequalities. Popular education. Health.

\footnotetext{
${ }^{1}$ Doutora em Ciências (FIOCRUZ), Universidade Federal Fluminense (Niterói/RJ), lucianacollier@gmail.com

${ }^{2}$ Graduanda em Serviço Social (UFF), Universidade Federal Fluminense (Niterói/RJ), victorialivramento@gmail.com

${ }^{3}$ Graduanda em Serviço Social (UFF), Universidade Federal Fluminense (Niterói/RJ), carolinadml@id.uff.br

${ }^{4}$ Graduanda em Serviço Social (UFF), Universidade Federal Fluminense (Niterói/RJ), marinsjuliane.jm@gmail.com
} 


\section{Introdução: nosso ponto de partida}

A pandemia do coronavírus (COVID-19) se difundiu globalmente com extrema rapidez ao longo do ano de 2020 (OMS, 2020). De março de 2020 até fevereiro de 2021, segundo a Organização Pan-Americana da Saúde (OPAS) foram contabilizados mais de 2 milhões de mortos e 107 milhões de casos notificados no mundo. Além de um maior rigor com os hábitos de higiene, a principal modificação que a pandemia do COVID-19 trouxe para a vida cotidiana foi o distanciamento social.

Com o objetivo de reduzir a transmissão do vírus, diversos países implementaram medidas rígidas de controle sobre o deslocamento das pessoas nas cidades, reduzindo ao máximo o contato próximo entre as mesmas. A população foi aconselhada a se isolar em casa; reuniões sociais de qualquer espécie foram proibidas; atividades laborais consideradas 'não essenciais' foram suspensas ou passaram a ser realizadas de maneira virtual ou sob o regime de home office; escolas, faculdades e universidades foram fechadas; o transporte público foi reduzido (em alguns casos suspenso), bem como todo movimento populacional 'não essencial' (DOUGLAS et al., 2020).

Apesar do impacto destas medidas no que tange à disseminação do vírus, como achatamento da curva de contágio e redução da sobrecarga dos serviços de saúde, é importante ressaltar que o distanciamento social, por tempo prolongado, pode provocar sérios danos econômicos, sociais e psicológicos. A quarentena de pessoas expostas a uma doença infecciosa está associada a efeitos psicológicos negativos, semelhantes aos sintomas de estresse póstraumático, que podem ser duradouros (BROOKS et al., 2020). Sensações como medo, incerteza e insegurança, provocam um aumento nos níveis de ansiedade e depressão. Epidemias anteriores (Ébola, HIV, H1N1, etc.) demonstram que o número de pessoas cuja saúde mental é afetada tende a ser maior que o número de pessoas infectadas e que as implicações para a saúde mental podem durar mais tempo e ter maior prevalência que a própria epidemia (SCHIGEMURA et al. 2020).

Para Ornell et al. (2020), além do medo concreto da morte, a pandemia do COVID-19 afetou a organização das famílias, das escolas e das empresas, gerando mudanças profundas nas rotinas de trabalho e estudo. De igual magnitude foram os efeitos do distanciamento social, levando a sentimentos de desamparo e abandono, bem como a insegurança, devido às repercussões econômicas e sociais que a situação impôs a toda sociedade.

No que tange aos efeitos econômicos da pandemia nas diferentes sociedades, é importante levar em conta que a renda de cada cidadão determina as suas possibilidades de aquisição de bens para a vida e acesso a recursos (alimento, moradia, remédios, produtos de higiene, etc.) que impactam na saúde. No Brasil, durante o período das medidas rígidas de distanciamento social, uma parcela da população não teve direito a permanecer em casa, cuidando de si e da sua família. Alguns tiveram que sair para trabalhar, mesmo em atividades não essenciais, enquanto outros perderam seu emprego e sua renda. Alguns puderam isolar-se no lar, sem que isso gerasse perdas financeiras consideráveis. Para evitar o aumento das desigualdades, as medidas de distanciamento social tiveram que ser acompanhadas de medidas financeiras, sob o formato de políticas públicas, para salvaguardar a renda das pessoas mais pobres (DOUGLAS et al. 2020; SILVA et al. 2020). De maneira geral, quanto menos desigualdade e maior reserva financeira, mais eficazes foram as medidas econômicas implementadas por cada país. No bojo das medidas restritivas de distanciamento social, as desigualdades socioeconômicas se exacerbaram, privilegiando as classes sociais mais altas em detrimento dos mais pobres.

No âmbito da educação, levando-se em consideração as medidas restritivas de distanciamento social, escolas e universidades tiveram suas atividades suspensas de forma abrupta, o que acabou por gerar incerteza e ansiedade no conjunto da sociedade. As alternativas 
para a manutenção do contato entre estudantes e escola/universidade, foram sendo construídas ao longo da pandemia, conforme as medidas restritivas foram sendo definidas. No Brasil, poucas escolas e universidades, bem como seus docentes, já possuíam estrutura e experiência de ensino à distância (EAD), para substituir imediatamente o ensino presencial. Apesar disso, o Ministério da Educação (MEC) publicou em março de 2020 a Portaria 143, autorizando o ensino emergencial, com substituição das aulas presenciais por aulas em meios digitais enquanto durasse a situação de pandemia (BRASIL, 2020). Para a definição dessas medidas os menos consultados, ouvidos ou considerados foram os professores, estudantes e suas famílias (MONTEIRO, 2020).

Passado um ano, o grande desafio do momento é distribuir as vacinas que foram produzidas de forma célere, à maioria da população mundial, bem como desenvolver novas drogas e protocolos de tratamento para cuidar dos infectados - especialmente os casos mais graves -, aumentando as chances de sobrevida. Paralelamente, mutações do vírus têm sido identificadas e estudadas em diferentes centros de pesquisa do mundo, a fim de controlar a sua disseminação. Enquanto isso não se concretiza, a manutenção de medidas de distanciamento social para diminuir as consequências da disseminação do COVID-19 permanece sendo uma necessidade, com protocolos de flexibilização das regras, sendo experimentados com maior ou menor sucesso nos diferentes países do mundo, inclusive no Brasil.

As consequências negativas da pandemia do novo coronavírus são inevitáveis e mais devastadoras entre a população economicamente vulnerável. Dessa forma, é mister que essas pessoas sejam ouvidas, para que suas demandas urgentes sejam compreendidas, a fim de subsidiar a elaboração e implementação de políticas públicas que possibilitem uma melhoria das suas condições de vida e saúde. Nesse processo de escuta, as estratégias de educação popular em saúde, abrem um vasto leque de possibilidades.

De acordo com Moreira et al. (2007) a educação popular em saúde une os conceitos de educação em saúde e educação popular visando à construção coletiva de conhecimentos e caminhos para a superação das iniquidades sociais que impactam negativamente a saúde dos sujeitos e das coletividades. A educação em saúde faz parte das estratégias de promoção da saúde que priorizam o empoderamento coletivo e a educação popular, dentro dos princípios da educação freireana, se baseia no diálogo, na problematização, na troca de saberes e na conscientização dos sujeitos, enquanto mediação para a autonomia e a autoria do mundo.

A educação popular em saúde ultrapassa a noção de educação em saúde como orientação e informação para a aprendizagem de bons hábitos. Evoca a dimensão da educação libertadora de Paulo Freire contribuindo com o empoderamento comunitário, que se traduz na participação e controle dos indivíduos e comunidades na definição de ações coletivas para a efetiva melhoria da qualidade de vida.

Neste artigo descrevemos as ações desenvolvidas pelos bolsistas do projeto "A COVID19 e a determinação social da saúde" , analisando seus desdobramentos sob a luz da teoria da determinação social da saúde e da educação popular em saúde.

\section{Nosso embasamento teórico}

O ano de 2020 foi interrompido pela pandemia do coronavírus. Com universidades, escolas, comércio e serviços não essenciais paralisados e sem data para voltar, a população ficou atônita. Face ao panorama vivido, o projeto "COVID 19 e a determinação social da saúde"

\footnotetext{
${ }^{5}$ O projeto "A Covid-19 e a determinação social da saúde" foi uma ação de ensino, pesquisa e extensão, desenvolvida numa escola pública federal localizada em Niterói/RJ no ano de 2020. O projeto contou com 6 bolsistas e um voluntário, sendo: 2 alunos do ensino fundamental e 2 alunos do ensino médio dessa escola e 3 alunas do curso de graduação em Serviço Social de uma universidade federal de Niterói (sendo uma voluntária).
} 
foi criado a fim de discutir com a comunidade de uma escola pública federal, localizada em Niterói/RJ, as condições de saúde e vulnerabilidade social impactadas pela pandemia, provocando reflexões e ações sobre as iniquidades em saúde.

De acordo com Silva et al. (2020), no Brasil estamos vivendo uma tríplice pandemia econômica, política e sanitária -, que precisa provocar reflexões profundas acerca dos valores e atitudes individuais e coletivas de toda sociedade. Nesse contexto é que se amplifica a necessidade histórica de implantação de estratégias de melhoria de vida da população, não só durante a pandemia, como também após sua passagem. Urge a necessidade de adoção de políticas socioeconômicas de maior impacto na vida dessas pessoas e com maior abrangência, ampliando o acesso a melhores condições de saúde, educação, moradia e renda (ESTRELA et al., 2020).

No âmbito do distanciamento social, quando todas as ações educacionais presenciais foram suspensas, muitas orientações sobre o controle da disseminação do vírus foram divulgadas incessantemente em todos os veículos de comunicação. Muitas não faziam sentido no contexto de vida da população mais vulnerável. Ficar em casa e não aglomerar, mas dentro de casas pequenas com muitos membros familiares no mesmo cômodo, a aglomeração era maior. Manter a higiene das mãos lavando-as sempre ou higienizando-as com álcool, mas em locais onde a água é escassa na torneira e onde a renda mal dá para a alimentação, o álcool em gel é um luxo. O saber científico - conteúdo de parte das informações disseminadas através dos veículos de comunicação e redes sociais - precisava urgentemente dialogar com o saber popular, para que os diferentes sujeitos pudessem compreender tais informações. Para Camacho et al. (2020) o Brasil carece de políticas e ações focadas na literacia da saúde, que se relaciona com a dificuldade de compreensão das indicações divulgadas pelas autoridades de saúde. Além disso, medidas urgentes de melhoria das condições de saneamento básico e acesso à água canalizada, ou de acesso a cuidados de saúde em comunidades carentes precisam ser tomadas.

Logo que as escolas conseguiram organizar estratégias virtuais de contato com as comunidades escolares, os relatos dos estudantes e de suas famílias eram de medo e insegurança da situação desconhecida; dúvidas sobre a veracidade das informações veiculadas; ansiedade e angústia por não saber quando a vida voltaria ao 'normal'; tensão e cansaço pelas restrições impostas pela quarentena. Ninguém sabia exatamente o que era, quando ia acabar e nem a proporção do problema, mas sem dúvida, o que mais preocupava a todos, era saber como se defender do vírus.

O papel da escola no início da pandemia foi de acolher, escutar e manter o vínculo afetivo entre os membros das comunidades escolares. No âmbito da educação pública brasileira, o momento era de pensar junto com as comunidades escolares sobre as mazelas da desigualdade social evidenciadas com a Covid-19. Atividades pedagógicas pautadas exclusivamente na transferência de conhecimentos, deixaram de fazer sentido e seguir com os conteúdos escolares, tentando fazer funcionar o ensino à distância na Educação Básica, sem contextualizar com a condição de vida dos estudantes, mostrou ser inócuo, aprofundando as desigualdades. Era urgente pensar em estratégias pedagógicas dialógicas, baseadas na educação popular freireana, com foco na troca de saberes e experiências.

Diferente da 'educação bancária', a educação popular e libertadora, não compreende os estudantes como seres vazios a quem a escola e o conhecimento científico depositam conteúdos. Entendemos que os sujeitos que compõem a comunidade escolar devem ser considerados como sujeitos conscientes e participantes ativos das decisões que interferem em suas vidas (FREIRE, 2005). Portanto, a solução para as demandas comunitárias, não pode vir na forma de receita, mágica ou imposição, precisa emergir do conhecimento popular, construído no diálogo e tradução com o conhecimento científico, a fim de que seja libertador. Se esses princípios já eram importantes no contexto educacional antes da pandemia, passaram a ser pré-requisito para 
qualquer ação pedagógica à distância, quando adolescentes e crianças ficaram privados do contato com o ambiente escolar.

Durante o período mais grave da pandemia, quando ninguém podia sair de casa para trabalhar, a incerteza sobre a questão financeira gerou grande receio e intranquilidade, especialmente para as famílias mais pobres. Como a família teria recursos para se alimentar e para arcar com os cuidados com saúde, higiene, etc.? A preocupação era maior para as famílias em que um de seus membros era pessoa com doença crônica (diabetes, hipertensão, câncer, HIV, etc.), deficiência física ou intelectual, dadas as evidências de que as comorbidades aumentam a chance de contrair o vírus. $O$ sofrimento ficava ainda mais pungente, quando algum membro da família era internado ou falecia pela COVID-19. Sem poder ter contato nem se despedir do ente querido, a dor das famílias foi imensurável.

Nesse contexto, se complexifica o debate sobre a concepção de saúde. Para muitos, a saúde pode ser entendida como uma questão restrita a fatores biológicos, sendo esta uma concepção hegemônica, que perpetua práticas e conhecimentos que minimizam a importância dos fatores sociais na vida dos indivíduos. Uma outra linha de raciocínio explica a saúde como um fenômeno complexo e com múltiplas determinações, que tem suas bases na forma como vivemos e nos organizamos enquanto sociedade (PETTRES e DA ROS, 2018). A pandemia da COVID-19 mostrou ao mundo que a segunda hipótese, explica melhor a ideia de saúde.

A sociedade capitalista, através da sua organização social e do seu modo de produção, acentua a reprodução das iniquidades sociais. A estrutura e organização dos sistemas de saúde, apoiados nessa concepção, perpetuam práticas que não conseguem responder aos problemas de saúde/doença da população, desdobramento que são das contradições sócio-político-culturais do capitalismo (PETTRES e DA ROS, 2018).

Foi exatamente o que pudemos observar em diferentes países do mundo durante a pandemia. Apesar da necessidade de distanciamento e isolamento social, a parcela mais pobre e, consequentemente, mais vulnerável da população ficou mais exposta ao risco de contrair o vírus. Num primeiro momento, o coronavírus parecia não escolher classe social, mas depois provou que as pessoas que precisavam sair de casa para trabalhar ou, por motivos financeiros, não tinham acesso aos serviços básicos de higiene e saúde, ficaram mais expostas e adoeciam mais. Somado a isso, muitos perderam seu emprego ou sua renda, ficando, em alguns casos, sem a possibilidade de garantir alimentação e moradia para si e para sua família. Para Garbois, Sodré e Dalbello-Araujo (2017) a leitura dos fenômenos considerados de saúde inclui a forma de organização do trabalho como dimensão da determinação do processo de adoecimento, ao considerá-lo como o mediador das relações estabelecidas entre o homem e a natureza e entre os próprios homens.

Nesse sentido, a determinação social da saúde busca trazer a ideia de que a saúde é resultante das condições de alimentação, habitação, educação, renda, meio ambiente, trabalho, transporte, emprego, lazer, liberdade, acesso e posse da terra e acesso a serviços de saúde. Portanto, não pode ser considerada como um conceito abstrato, mas como resultado das formas de 'organização social da produção', as quais podem gerar grandes desigualdades nos níveis de vida. Define-se "no contexto histórico de determinada sociedade e num dado momento de seu desenvolvimento, devendo ser conquistada pela população em suas lutas cotidianas" (BRASIL, 1986, p.58). Breilh (2008) afirma que a determinação social da saúde pode ser explicada a partir dos "modos de viver historicamente estruturados e seus perfis de saúde, com a estrutura de propriedade e de acumulação, suas políticas de Estado e suas relações culturais" (p.4).

\section{Nossa proposta metodológica}

No bojo do contexto pandêmico do ano de 2020, o projeto "Covid-19 e a determinação social da saúde” foi criado e desenvolvido numa escola pública federal, no município de Niterói, 
Rio de Janeiro. Enquadrado como ação de ensino, pesquisa e extensão, o projeto utilizou ações de educação popular em saúde e pesquisa participante, para promover o debate e a reflexão crítica sobre os fatores sócioeconômicos que impactam na prevenção, disseminação e controle do novo coronavírus, bem como provocar reflexões sobre as iniquidades em saúde e construção coletiva de ações que possam minimizar os efeitos da pandemia sobre a saúde da comunidade escolar.

Pautados nos princípios da educação popular freireana, defendemos que o vínculo estabelecido entre escola e família, não deve se limitar à transmissão de conteúdos. Portanto, nossas ações de pesquisa sustentaram a realização de um mapeamento, a partir da prospecção das demandas prioritárias da comunidade escolar, originadas e aprofundadas no contexto da pandemia (DOUGLAS et al., 2020). Dessa forma, criamos condições para pensar em ações educativas significativas para os alunos, condizentes com o momento delicado que estamos vivendo. Somente elucidando as distintas realidades de vida da comunidade escolar, teremos condições de pensar em conhecimentos relevantes para os alunos.

Esse projeto se constituiu numa pesquisa qualitativa, com enfoque na estratégia do diagnóstico participativo, que buscou ampliar a participação da comunidade escolar nas discussões sobre as condições de saúde e vulnerabilidade social impactadas pela pandemia da COVID-19. De acordo com Sousa et al. (2018), a pesquisa participativa é um processo de investigação, educação e ação, que está atrelada à resolução de questões referentes aos problemas de populações marginalizadas e favorece o entendimento de várias questões sociais, incluindo as condições de saúde. Dessa maneira, possibilita o entrelaçamento de ações de pesquisa, ensino e extensão, na medida em que, através das metodologias participativas, coletamos dados, colaboramos com a formação e desencadeamos (re) ações para além dos muros da escola/universidade.

Dentro das estratégias metodológicas relacionadas à pesquisa participante, elencamos o diagnóstico participativo, que se constitui numa ferramenta que permite à população o direito de refletir sobre sua própria realidade, propiciando também a tomada de decisões coletivas e garantindo a participação no planejamento e implantação das políticas públicas (SOUSA et al., 2018). O diagnóstico participativo é adotado para captar os principais problemas de uma determinada localidade/comunidade, possibilitando a realização de um diagnóstico rico e fidedigno de um contexto social específico.

Para Weinstein et al. (2005), a utilização de várias estratégias de coleta de informações no diagnóstico participativo amplia o olhar do pesquisador, uma vez que a captação das informações é realizada a partir de diferentes referências, ao mesmo tempo que amplia a participação dos sujeitos do estudo. Nesse sentido, as ações utilizadas para a realização do mapeamento participativo também subsidiaram o desenvolvimento de ações educativas baseadas nas demandas e interesses da comunidade escolar. Além disso, a partir do contato e aproximação com o contexto de vida da comunidade escolar, tivemos a oportunidade de construir coletivamente outras estratégias e formatos de educação em saúde e divulgação científica.

De acordo com Moreira et al. (2007), inspirados em Paulo Freire, ações dessa natureza promovem o empoderamento comunitário, que se traduz na participação e controle dos indivíduos e comunidades na definição de ações coletivas para a efetiva melhoria da qualidade de vida. A escolha desse caminho implica o desenvolvimento da capacidade dos sujeitos de falar sobre os próprios problemas e situações que vivenciaram ou vivenciam e, mediados pelos diferentes agentes educativos, dialogar com outras bases de conhecimento. As ações educativas, comprometidas com essa proposta pedagógica, visam a uma reflexão crítica por parte dos sujeitos e das comunidades das quais participam, traduzidas em ações de transformação da realidade e superação das desigualdades sociais. 


\section{Nosso percurso de pesquisa}

Inicialmente o projeto em questão foi inserido em um edital de iniciação científica para alunos de escolas básicas. Após aprovação nesse edital, foram selecionados dois estudantes dos anos finais do ensino fundamental e dois do ensino médio, para desenvolverem as ações do projeto. Num segundo momento, o projeto foi aprovado em outro edital e passou a ser enquadrado no formato de ensino-pesquisa-extensão. Dessa forma, foram selecionadas e incorporadas ao grupo mais duas bolsistas e uma colaboradora voluntária, todas estudantes do curso de Serviço Social de uma universidade de Niterói/RJ.

Para levar a cabo o objetivo de discutir com a comunidade escolar sobre os fatores socioeconômicos que impactam na prevenção, disseminação e controle do novo coronavírus, os bolsistas realizaram as seguintes ações:

a) desenvolveram um questionário para a coleta de dados sobre o impacto das iniquidades sociais na saúde da comunidade escolar,

b) construíram materiais e ações de informação e educação em saúde baseados nas demandas dos estudantes da escola e suas famílias, e

c) organizaram rodas de conversa com a comunidade escolar e especialistas em assuntos que a própria comunidade elencou como sendo importantes para o momento.

Seguindo essa linha de ação, nas primeiras reuniões dos bolsistas com a orientadora, foi priorizada a busca por artigos e informações qualificadas, para que fosse feita a leitura, reflexão e debate sobre as relações entre a COVID-19 e as desigualdades sociais. Cada bolsista ficou encarregado de pesquisar sobre um tema específico: educação, vacina, trabalho e desemprego, curva de contágio e mortes, etc. e trazer a sua contribuição para nossas reuniões virtuais. Era fundamental que fosse estabelecida uma relação não hierárquica dentro do grupo, de forma que nossas decisões fossem coletivas, não impostas pela professora orientadora. Todos deveriam sugerir temas para estudo e propor ações para que pudéssemos construir estratégias de comunicação e ensino para toda comunidade escolar.

Utilizar o diálogo, a criatividade e a escuta atenta às demandas dos bolsistas, que estavam em constante contato com a comunidade, foi um fator imprescindível no planejamento das ações educativas do projeto. Concordando com Souza et al. (2020) colocamos como princípio das nossas ações a promoção de um cuidado empoderador e do bem-estar, contribuindo para a sobrevivência de quem cuida e de quem recebe o cuidado, como condição de uma vida digna para toda comunidade escolar.

Após alguns encontros de ampliação do debate, as sugestões e ideias para nos aproximarmos da comunidade escolar foram surgindo e sendo organizadas. Ficou decidido que, dado o momento de distanciamento social, seriam utilizadas três formas iniciais de comunicação com a comunidade: um blog (criado especificamente para o projeto) e duas redes sociais (Instagram e Facebook) ${ }^{6}$. Nesses veículos, semanalmente, eram inseridas postagens com informações essenciais e gratuitas à comunidade. Os temas das postagens emergiam das conversas dos quatro bolsistas da educação básica com seus colegas, em suas respectivas turmas. A cada encontro virtual do grupo de bolsistas com a orientadora do projeto, eles traziam dúvidas e questionamentos que estavam sendo discutidos entre os estudantes nos diferentes grupos de WhatsApp.

Dialogando com a educação proposta por Freire, nosso projeto se desenvolveu com base na criatividade e estímulo à reflexão e à ação dos homens e das mulheres sobre a realidade, dentro de seus limites e possibilidades. Ela ocorreu num "esforço permanente através do qual homens vão se percebendo, criticamente, como estão sendo no mundo" (FREIRE, 2005, p.82). Para isso, foi necessária uma investigação do "universo temático do povo", ou "conjunto de

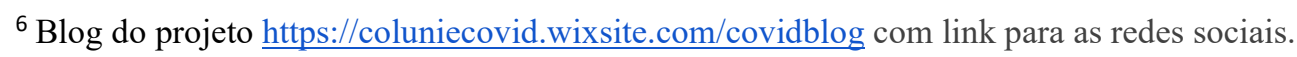


seus temas geradores", mediante a utilização das redes sociais e outros recursos virtuais de comunicação com a comunidade escolar que, naquele momento, representavam a única forma de contato possível.

Para dar continuidade às ações informativas e de educação, era imprescindível saber como a comunidade escolar, afastada do convívio presencial por conta das medidas de distanciamento, estava vivendo e sobrevivendo durante a pandemia. Era fundamental nos aproximarmos da realidade que estavam vivenciando os estudantes e suas famílias, conhecer o seu pensamento e os níveis de percepção que alcançavam do contexto da pandemia, utilizando a mesma linguagem por eles utilizada (FREIRE, 2005).

Iniciamos o levantamento de dados com a comunidade escolar, através do envio de um questionário virtual (Google Forms), pela secretaria da escola a toda comunidade escolar (alunos e responsáveis, professores e funcionários), com a descrição dos objetivos do projeto e o termo de consentimento e participação na pesquisa. Além da caracterização da comunidade (cor de pele, número de pessoas por residência, faixa salarial, cidade onde vive), o questionário buscava levantar as demandas urgentes: quem havia perdido emprego e renda, quem havia contraído a doença, se havia familiares que faleceram, como estavam lidando com as restrições sanitárias, orçamentárias e com o distanciamento social? No total foram enviados 487 questionários (um para cada família de aluno, funcionário e docente), dos quais obtivemos o retorno de 212 famílias.

As maiores dificuldades relatadas pelas famílias durante o período do distanciamento social foram a manutenção do distanciamento social $(42,5 \%)$ e a financeira $(38,2 \%)$, sendo mencionadas em menor número as dificuldades de acesso aos serviços de saúde $(9,4 \%)$ e de assistência social $(5,1 \%)$. No final do questionário destinamos um espaço para relatos de necessidades não perguntadas anteriormente. Nesse espaço, 20 pessoas solicitaram ajuda relativa à saúde mental própria ou de familiares e 8 pessoas relataram outras situações graves de saúde na família. De posse dessas informações decidimos que era urgente pensar em ações de diálogo e suporte para as famílias.

A concepção de educação problematizadora, cujo pressuposto básico prevê que "os homens se educam em comunhão, mediatizados pelo mundo" (FREIRE, 2005, p.79), tem caráter reflexivo, implicando um constante ato de desvelamento da realidade, buscando uma inserção na realidade, conduzindo à mudança (MOREIRA et al., 2007). Portanto, não nos contentamos em analisar os dados coletados através do questionário somente dentro do nosso grupo de pesquisa. Nossa proposta tratava da realização de um diagnóstico participativo, logo, nas reuniões seguintes, os bolsistas foram mobilizados a sugerir e elaborar ações que fossem ao encontro das demandas levantadas através do questionário virtual, mas que, por outro lado, aprofundassem o diálogo com a comunidade.

Para que pudéssemos dialogar de forma isonômica, respeitando as questões de diversidade e acessibilidade e atender as demandas dos estudantes em situação de vulnerabilidade social e de suas famílias, um grupo ficou responsável por pesquisar informações qualificadas sobre os temas suscitados no questionário e elaborar novas postagens para serem divulgadas nas redes sociais e blog do projeto, outro grupo ficou encarregado de organizar as rodas de conversa entre a comunidade escolar e profissionais especializados nos assuntos.

O blog e as redes sociais do projeto foram bastante efetivos na ação de articular o conhecimento científico e o contexto de saúde e vida da comunidade escolar. Para cada assunto demandado pela comunidade, os bolsistas pesquisaram sobre os temas em referenciais teóricos, mas também entrevistaram estudantes, professores e outros membros da comunidade, sobre questões que foram aparecendo durante o projeto.

As entrevistas aconteceram de forma individual, através de aplicativos de conversa por celular, em áudio, vídeo ou por escrito, dependendo da disponibilidade e acesso à tecnologia 
do entrevistado e do entrevistador. Dado um tema de grande repercussão na mídia e que dialogava com a análise das respostas do questionário (ensino remoto emergencial, trabalho presencial, saúde mental, vacinação), fazíamos um levantamento de nomes de pessoas da comunidade que poderiam falar, explicar ou dar a sua opinião. Decidíamos dentro do grupo quem seria(m) o(s) entrevistado(s) e que questões deveriam ser feitas. A partir das falas e das ideias dos entrevistados e matérias divulgadas na mídia sobre o mesmo tema, elaboramos algumas postagens para o blog e para as redes sociais.

Dessa forma, o ritmo dinâmico e acelerado do contexto pandêmico foi sendo abordado a partir de distintas nuances e olhares. Esses novos olhares sobre as temáticas abordadas problematizam e contribuem para a transformação social, na medida em que reorganiza a relação de todos os participantes por meio de novas experiências de cuidar da saúde em condições de exceção (BARROS; OLIVEIRA; SILVA, 2007).

Pensando numa educação diferente da educação bancária, buscando fugir das amarras da transmissão unilateral de conhecimento, pensamos na realização de rodas de conversa. Foram realizadas ao longo do projeto três rodas de conversa: a primeira sobre o tema "Trabalho e renda em tempos de pandemia", a segunda sobre "Saúde mental e emocional em tempos de pandemia" e a terceira sobre "Ensino remoto e saúde mental em tempos de pandemia e perspectivas futuras". O tema do terceiro encontro surgiu de uma enquete à parte, realizada com essa finalidade específica junto à comunidade escolar. Já havíamos percebido um desgaste muito grande dos estudantes e professores e uma grande inquietação das famílias com o futuro das relações escolares. $\mathrm{O}$ resultado da enquete foi assertivo nesse sentido.

Para cada roda de conversa, era convidado um profissional "especialista" no tema e toda a comunidade escolar: alunos, professores, funcionários e familiares. Nossa prioridade era a superação da contradição educador-educandos (ou especialista-leigo) colocando o conhecimento como o mediador dos sujeitos envolvidos na ação educativa (FREIRE, 2005). Para tanto, os especialistas convidados eram parceiros do projeto, com os quais conversamos previamente, para explicar a proposta do projeto, as demandas colocadas e a metodologia que seria empregada para o desenvolvimento da roda. Alimentados pelas ideias da educação popular em saúde, buscamos, através das rodas de conversa, desenvolver a capacidade dos indivíduos de falar sobre os próprios problemas e os processos que vivenciaram, visando a uma reflexão para uma ação crítica sobre a realidade se constituindo numa descontinuidade da lógica hegemônica do modelo de saúde vigente, de cunho reducionista (MOREIRA et al., 2007).

Nessas rodas de conversa foi priorizado o diálogo , "selo" do processo educativo, desvelador da realidade, e, por isso, imprescindível na educação problematizadora, comprometida com a libertação dos sujeitos. O "diálogo freireano" promove uma interação entre o saber científico e o saber popular, em que os sujeitos envolvidos aprendem e ensinam, mediatizados pelo mundo, nos remetendo a pensar no ser humano como um sujeito em construção e, na educação, como um processo de troca. Esse diálogo busca promover a reflexão com respeito à autonomia, no qual partindo de um problema real, o sujeito se sinta desafiado e busque uma resposta, no nível intelectual, mas, sobretudo, no nível da ação (MOREIRA et al., 2007).

Dessa forma, o convidado "especialista" apresentava de forma breve o seu conhecimento sobre o tema e depois escutava e dialogava com os demais participantes da roda, sem a preocupação de trazer respostas para as questões apresentadas. Em algumas rodas, as sugestões e respostas emergiram da própria interação dos participantes, reafirmando as palavras de Valla (2000) de que é preciso levar em conta o que as pessoas pensam sobre os próprios problemas e que soluções coletivas vislumbram.

Diante da necessidade de que as ações de educação popular em saúde levem em conta o sentido da vida e o controle sobre a vida por parte das pessoas, o mesmo autor reafirma a necessidade da solidariedade comunitária. Nessa perspectiva, a partir do debate sobre o 
desemprego que permeou nossas rodas de conversa, pudemos perceber que além de ser uma demanda urgente, é um fator que afeta diretamente a saúde mental dos sujeitos. As famílias não queriam somente se informar e conversar sobre o tema "trabalho e renda", mas queriam criar ações de solidariedade, que pudessem atender emergencialmente os que haviam perdido sua renda. Foi criada então uma rede de solidariedade virtual, baseada na divulgação de produtos e serviços oferecidos por qualquer membro da comunidade escolar em nossos canais de comunicação (blog e redes sociais). A intenção era sugerir que a própria comunidade buscasse esses produtos e serviços entre os próprios membros da comunidade.

\section{Nossa comunidade escolar por ela mesma: o diagnóstico participativo}

A análise das respostas dadas pelas famílias que responderam ao nosso questionário demonstrou que a perda de emprego e renda havia sido muito acentuada e que a saúde mental e emocional estava bastante abalada. Segundo Camacho et al. (2020) a vulnerabilidade social das famílias se acentuou muito durante a pandemia e a falta de estrutura e de preparo para lidar com tecnologias da informação e comunicação foi um fator limitante da nossa investigação. Muitos sequer dispunham dos recursos mínimos para acessar redes sociais, aplicativos de conversa ou salas virtuais. Somadas às situações de vulnerabilidade estrutural, a exposição ao risco de contágio e a incapacidade de acessar as ferramentas virtuais de informação, educação e comunicação, geraram um aumento nos casos de distúrbios emocionais e mentais no contexto da pandemia da COVID-19.

De acordo com a teoria social crítica, o modo de produção capitalista tem como traço constituinte a Lei do Valor. Segundo Netto e Braz (2008), o trabalho que emancipa o homem torna-se, nesse modo de produção, alienado e explorado. A classe trabalhadora, expropriada dos meios de produção, tem como única forma de sobrevivência a venda da sua força de trabalho, a qual, muitas vezes não encontra comprador. Essa parcela populacional se encontrará em situação de desemprego, formando o que Engels designou como "exército industrial de reserva". Para Netto e Braz (2008), trata-se de um impacto da acumulação do capital na classe operária, "um componente necessário e constitutivo da dinâmica histórico-concreta do capitalismo" (p.145). Esse contingente de desempregados pressiona as condições de trabalho para baixo.

É possível perceber a centralidade que a temática do trabalho e da renda tomou no contexto da pandemia do novo coronavírus. Para as famílias de alunos, professores e funcionários da escola em questão, uma das maiores dificuldades foi a questão financeira, tendo em vista que a necessidade do isolamento social impossibilitou que os indivíduos realizassem suas atividades remuneradas, já precarizadas, de forma regular.

Numa questão inicial, perguntamos se tinha ocorrido alguma perda na renda familiar e as respostas apontaram que $58,5 \%$ das famílias haviam tido uma diminuição da renda familiar durante a pandemia. Desse percentual, $74 \%$ ainda não havia recuperado totalmente a renda, enquanto $14 \%$ havia recuperado parcialmente a renda relativa ao período anterior à pandemia. Numa outra questão, a dificuldade financeira foi apontada por $38,2 \%$ das famílias como sendo uma das maiores dificuldades enfrentadas durante o ano de 2020. Tal dificuldade acaba por gerar a necessidade de mais membros dessas famílias (inclusive os próprios estudantes) em sair de casa para trabalhar e se expor ao vírus, evidenciando a precariedade das condições de trabalho. Sair para trabalhar foi o motivo apontado por $82,8 \%$ das famílias para não cumprir as medidas de distanciamento social.

Podemos perceber que a estrutural precariedade das condições de trabalho se encontra de maneira ainda mais complexa nesse momento de pandemia devido à ausência da intervenção do Estado e de direitos relacionados ao trabalho, ocasionando uma grande dificuldade por parte das famílias em relação à renda. Apesar de o desemprego, a exploração e a precariedade do 
trabalho serem aspectos estruturais do modo de produção regido pelo capital, estudos mostram que, no século XXI, há uma conjuntura ainda mais problemática no mundo do trabalho (DRUCK, 2011; CEOLIN, 2014). A classe trabalhadora tem na venda da sua força de trabalho a única maneira de sobreviver. Esse grande contingente populacional, no entanto, na busca por sobrevivência, se depara com relações trabalhistas instáveis e precárias, com uma crescente retirada de direitos devido à onda neoliberal desde dos anos 90, a qual afeta drasticamente a condição de vida dessa classe. De acordo com Antunes (2018), os que conseguem se manter empregados sofrem com a negação dos seus direitos sociais e suas conquistas históricas devido à lógica destrutiva do capital, a qual expulsa trabalhadores de sua única forma de sobrevivência e criam novas modalidades de trabalho marcados pela informalidade, flexibilização e precarização.

Considerando que o capitalismo não é só uma realidade econômica, como também política, social, ideocultural, e atinge vários âmbitos da vida social e as suas relações, é necessário refletir sobre os impactos desse modo de produção no processo de adoecimento mental e emocional. Com a intensificação da precarização do trabalho e o agravamento das desigualdades sociais, $14,8 \%$ das famílias relataram dificuldades em lidar com a saúde mental e emocional, e 5,5\% apontaram outros problemas graves de saúde em consequência do período pandêmico.

Numa realidade em que mais da metade das famílias tiveram suas rendas reduzidas (configurando uma intensa insegurança financeira), o aumento das exigências da produtividade, a invasão do tempo de trabalho (home office), as aulas remotas no ambiente domiciliar e as mudanças no funcionamento do modo de vida resultaram em relatos que apontam para o desgaste mental e emocional da comunidade escolar.

Para entender as repercussões psicológicas e psiquiátricas de uma pandemia, todas as emoções afloradas devem ser consideradas e observadas atentamente. Nessas situações, o medo de contrair a doença aumenta os níveis de ansiedade e estresse em indivíduos saudáveis e intensifica os sintomas daqueles com transtornos psiquiátricos pré-existentes (ORNELL et al., 2020). Tais condições podem evoluir para transtornos depressivos ou de ansiedade (incluindo ataques de pânico e estresse pós-traumático), psicóticos ou paranoides, e podem até levar ao suicídio. Nesse contexto, as consequências psiquiátricas de uma pandemia podem ser significativamente altas, sobrecarregando os serviços de emergência e o sistema de saúde como um todo (SHIGEMURA et al., 2020).

Do ponto de vista de uma pandemia, não basta compreender o sujeito a partir de uma perspectiva puramente biológica e pedir que ele lave as mãos, use máscara e se distancie dos demais. É necessário considerar também os aspectos econômicos, sociais e culturais que se organizam dentro do modo de produção capitalista e contribuem com os processos de adoecimento psicossocial. A instabilidade constante que o capitalismo se encontra em relação às questões de desemprego, a exploração da força de trabalho, o sucateamento da educação pública e do Sistema Único de Saúde, são fatores fundadores do processo de adoecimento psicossocial.

\section{Nosso projeto por nós mesmos}

Desde o começo, mesmo diante da dificuldade de estarmos fisicamente afastados e tendo que organizar todas as ações virtualmente, o projeto sempre foi organizado coletivamente. Logo no princípio, decidimos que todos poderíamos expor nossas opiniões sobre o desenvolvimento das ações. Passamos alguns meses pesquisando, escrevendo e debatendo, buscando a melhor maneira de entrar em contato com a comunidade para dialogar com seus membros. 
Durante o desenvolvimento do projeto surgiram algumas complicações, pois tínhamos muitas ideias e não podíamos realizar todas. O distanciamento social, a dificuldade da comunidade em ter acesso à internet, as famílias que enfrentavam problemas que estavam fora do nosso alcance, o tempo escasso para desenvolver ações mais aprofundadas. Muitas das nossas ideias tiveram que ser adaptadas às condições que estávamos vivendo e se distanciaram um pouco daquilo que pretendíamos realizar no princípio.

Apesar disso, conseguimos compartilhar informações qualificadas, fortalecendo o sentido de coletividade e solidariedade em nossa comunidade escolar. Tivemos um bom alcance e visibilidade nas redes sociais e pudemos perceber que, por meio de ações de educação e comunicação é possível promover o debate sobre as desigualdades sociais que impactam a saúde. Os encontros virtuais também foram uma ferramenta fundamental para o diálogo e a troca de informações e para o acolhimento dos sujeitos que compõem a comunidade escolar.

O mapeamento da comunidade demonstrou um aprofundamento das iniquidades sociais que impactam a saúde. A pandemia e seus desdobramentos, retiraram de grande parcela da nossa comunidade o controle sobre suas condições objetivas de vida (trabalho, renda, poder de compra, direito de ir e vir) e os fatores subjetivos (medo, ansiedade, desânimo, solidão) foram desconsiderados. A escola e o trabalho invadiram os lares, vulnerabilizando ainda mais aqueles e aquelas que não tinham condições materiais e emocionais de acesso às ferramentas digitais de educação e comunicação. Alunos, professores, funcionários e familiares tiveram seus direitos subjetivos minimizados ou ignorados, em prol da manutenção da produtividade do sistema capitalista. Sem condições de superar as dificuldades do momento, alguns foram culpabilizados, outros acabaram entrando em processo de adoecimento psicossocial.

Do ponto de vista da evolução de cada um dos bolsistas envolvidos na pesquisa, a estrutura metodológica do projeto ajudou a desenvolver o interesse pelas atividades relacionadas com a pesquisa científica, tais como ler, analisar criticamente as informações e escrever sobre o assunto. Além de fomentar a capacidade de escutar as pessoas e perceber as diferentes formas de expressão dos problemas sociais que permeiam a realidade dos sujeitos. Isso foi possibilitado pela troca de conhecimentos entre todos envolvidos no desenvolvimento do projeto. Estivemos juntos nesse período, ensinando e aprendendo uns com os outros, entre nós e com a nossa comunidade, mas firmes no objetivo de nos fortalecer mutuamente contra todo tipo de ataque, de um vírus ou do sistema capitalista, que insistem em aprofundar as desigualdades sociais no mundo.

\section{Referências}

ANTUNES, Ricardo. O privilégio da servidão: o novo proletariado de serviço na era digital. Boitempo editorial, 2018.

BARROS, Sônia; OLIVEIRA, Márcia Aparecida Ferreira; SILVA, Ana Luisa Aranha. Prácticas innovadoras para el cuidado en la salud. Rev. esc. enferm. USP [on-line], v.41, n.spe, p.815-819. 2007. DOI: https://doi.org/10.1590/S0080-62342007000500013.

BOURGOIS, Philippe et al.. Structural vulnerability: operationalizing the concept to address health disparities in clinical care. Academic medicine: journal of the Association of American Medical Colleges, v. 92, n. 3, p. 299, 2017. Disponível em: https://www.ncbi.nlm.nih.gov/pmc/articles/PMC5233668/. Acesso em: 20 fev. 2021.

BRASIL. Relatório Final da VIII Conferência Nacional de Saúde. Brasília: Ministério da Saúde, 1986. Disponível em: 
https://bvsms.saude.gov.br/bvs/publicacoes/8_conferencia_nacional_saude_relatorio_final.pdf . Acesso em: 2 mar. 2021.

BRASIL. Portaria no 343, de 17 de março de 2020. Dispõe sobre a substituição das aulas presenciais por aulas em meios digitais enquanto durar a situação de pandemia do Novo Coronavírus - COVID-19: Ministério da Educação, 2020. Disponível em: https://www.in.gov.br/en/web/dou/-/portaria-n-343-de-17-de-marco-de-2020248564376\#: :text=Disp\%C3\%B5e\%20sobre\%20a\%20substitui\%C3\%A7\%C3\%A3o\%20das ,Constitui $\% \mathrm{C} 3 \% \mathrm{~A} 7 \% \mathrm{C} 3 \% \mathrm{~A} 3 \mathrm{o} \% 2 \mathrm{C} \% 20 \mathrm{e} \% 20$ considerando $\% 20 \mathrm{o} \% 20$ art. Acesso em: $20 \mathrm{fev}$. 2021.

BREIHL, J. Una Perspectiva Emancipadora de la Investigación y Acción, Basada en la Determinación Social de la Salud. Asociación Latinoamericana de Medicina Social. Taller Latinoamericano sobre Determinantes Sociales de la Salud: documento para la discusión. México, D.F.: ALAMES, 2008. 155 p. Disponível em: https://repositorio.uasb.edu.ec/bitstream/10644/3413/1/Breilh,\%20J-CON-119Una\%20perspectiva\%20em.pdf. Acesso em: 15 fev. 2021.

BROOKS, Samantha K. et al.. O impacto psicológico da quarentena e como reduzi-la: revisão rápida das provas. Lancet, v. 395, p. 912-20, 2020. DOI: https://doi.org/10.1016/S01406736(20)30460-8

CAMACHO, Alessandra Conceição Leite Funchal et al.. Alunos em vulnerabilidade social em disciplinas de educação à distância em tempos de COVID-19. Research, Society and Development, v. 9, n. 7, p. e275973979, 2020. DOI: https://doi.org/10.33448/rsd-v9i7.3979

CEOLIN, George Francisco. Crise do capital, precarização do trabalho e impactos no Serviço Social. Serv. Soc. Soc., São Paulo , n. 118, p. 239-264, June 2014. DOI: https://doi.org/10.1590/S0101-66282014000200003

DOUGLAS, Margaret et al.. Atenuar os efeitos de saúde mais amplos da resposta pandêmica da Covid-19. Bmj, v. 369, 2020. Disponível em https://www.scielo.br/pdf/csc/v25n9/14138123-csc-25-09-3431.pdf. Acesso em: 6 mar. 2021.

DRUCK, Graça. Trabalho, precarização e resistências: novos e velhos desafios?. Cad. CRH, Salvador, v. 24, n. spe1, p. 37-57, 2011. DOI: https://doi.org/10.1590/S0103-49792011000400004

ESTRELA, Fernanda Matheus et al.. Pandemia da Covid 19: refletindo as vulnerabilidades à luz do gênero, raça e classe. Ciência \& Saúde Coletiva, v. 25, p. 3431-3436, 2020. DOI: https://doi.org/10.1590/1413-81232020259.14052020

FREIRE, P. Pedagogia do oprimido. 41. ed. Rio de Janeiro: Paz e Terra, 2005.

GARBOIS, Júlia Arêas; SODRÉ, Francis; DALBELLO-ARAUJO, Maristela. Da noção de determinação social à de determinantes sociais da saúde. Saúde em Debate, v. 41, p. 63-76, 2017. DOI:https://doi.org/10.1590/0103-1104201711206 
MONTEIRO, Sandrelena da Silva. (Re)inventar educação escolar no Brasil em tempos da COVID-19. Revista Augustus, v. 25, n. 51, p. 237-254, 2020. DOI:

https://doi.org/10.15202/1981896.2020v25n51p237

MOREIRA, J. et al. Educação popular em saúde: a educação libertadora mediando a promoção da saúde e o empoderamento. Revista Contrapontos, Itajaí, v. 7, n. 3, p. 507-521, 2009. Disponível em https://core.ac.uk/download/pdf/270172453.pdf. Acesso em: 18 fev. 2021.

NETTO, José Paulo; BRAZ, Marcelo. Economia Política: uma introdução crítica. 8 ed. São Paulo: Cortez, 2008.

ORGANIZAÇÃO PANAMERICANA DE SAÚDE. Saúde mental e considerações psicossociais durante o surto de COVID-19, 18 de março de 2020. PAHO, 2020. Disponível em https://iris.paho.org/handle/10665.2/51996. Acesso em: 10 fev. 2021.

ORGANIZAÇÃO PANAMERICANA DE SAÚDE. Folha informativa sobre COVID-19, Situação epidemiológica. PAHO, 2021. Disponível em https://www.paho.org/pt/covid19. Acesso em: 3 jul. 2021.

ORNELL, Felipe et al. "Pandemic fear" and COVID-19: mental health burden and strategies. Brazilian Journal of Psychiatry, v. 42, n. 3, p. 232-235, 2020. DOI: http://dx.doi.org/10.1590/1516-4446-2020-0008

PETTRES, Andreia Assmann; DA ROS, Marco Aurélio. A determinação social da saúde e a promoção da saúde. Arquivos Catarinenses de Medicina, v. 47, n. 3, p. 183-196, 2018. Disponível em http://www.acm.org.br/acm/seer/index.php/arquivos/article/view/375. Acesso em: 3 mar. 2021.

SHIGEMURA, J. et al. . Public responses to the new coronavirus 2019 (2019-nCoV) in Japan: consequences for mental health and target populations. Psychiatry Clin Neurosci [internet], v. 74, n. 4, p. 281-282, 2020. Disponível em https://pubmed.ncbi.nlm.nih.gov/32034840/. Acesso em: 12 mar. 2021.

SILVA, Maurício Roberto et al.. Bolsonaro e COVID-19: e daí? "O Brasil está matando o Brasill", "do Brasil, SOS ao Brasil", "chora a nossa pátria, mãe gentil ...". Motrivivência, v. 32, n. 62, p. 19/01/2020. DOI: https://doi.org/10.5007/2175-8042.2020e74507

SOUSA, Izautina Vasconcelos et al.. Pesquisa participativa no protagonismo comunitário para abordar questões de saúde: um olhar sobre o diagnóstico participativo. CIAIQ2018, v. 2, 2018. Disponível em https://www.proceedings.ciaiq.org/index.php/ciaiq2018/article/view/1880. Acesso em: 10 mar. 2021.

SOUZA, Claudia Teresa Vieira de et al. Cuidar em tempos da COVID-19: lições aprendidas entre a ciência e a sociedade. Cadernos de Saúde Pública, v. 36, p. e00115020, 2020. DOI: https://doi.org/10.1590/0102-311X00115020

VALLA, Victor Vicent. Educação e Participação Poupar-Revendo o debate em torno da participação popular: ampliando sua concepção em uma nova conjuntura. Doenças 
Endêmicas: abordagens sociais, culturais e comportamentais. Rio de Janeiro: Ed. Fiocruz, p. $253,2000$.

WEINSTEIN, Ana Lucia et al. Diagnóstico Comunitário Participativo: manual de ferramentas. Reino Unido: DIFD, 2005. 